\title{
Using seismoacoustic sounding technique for the purpose of structural integrity evaluation of the solid reinforced-concrete foundation for the power transmission line supports
}

\author{
Viktor Shabalin ${ }^{1, *}$, Boris Smishljaev ${ }^{1}$, Aleksandr Zhuravlev $^{1}$, and Jaroslav Sheetz ${ }^{1}$ \\ ${ }^{1}$ Far Eastern State Transport University, 47 Seryshev St,.Khabarovsk, 680021, Russia
}

\begin{abstract}
During construction of the monolithic reinforced-concrete foundation, it is not easy to monitor both a continuous haulage and technology of concrete placement. For that matter, some breach of the foundation structural integrity may occur. Currently, there is no unanimous integrated practice of monitoring concrete placement for building oversize solid reinforced-concrete foundations. The surveying results of the solid concrete foundation dimensioned $16 \mathrm{~m}$ by $16 \mathrm{~m}$ and from 2 to $3.5 \mathrm{~m}$ thick are set forth in the article. Such geophysical technique as seismoacoustic sounding has proved effective for concrete placement quality control of monolithic reinforced-concrete foundations by means of a non-destructive method.
\end{abstract}

\section{Introduction}

In the process of building foundations and structures that need a high volume of concreting operations, continuous concrete mix pouring over the entire surface area is required. Frequently enough, a project site and a concrete batch plant are separated by a considerable distance, while production of the prescribed mix in situ turns to be impossible. Under the circumstances, a contractor carries out pouring of concrete by means of several continuous concrete mixers. Nevertheless, when concreting pause happens to take place, some reasonable doubts concerning concrete placement quality for solid reinforcedconcrete foundation may occur. If the defects are not revealed and eliminated in due time, they may result in major social and ecological damage, setting aside the expenditures for the refurbishment of the foundation structural integrity and maintenance serviceability. Consequently, it is vitally important to monitor the technical state of engineering structures, to perform correct and timely evaluation, analysis, and forecast of possible defects, as well as to take well-timed measures of eliminating or repairing them.

Currently, such ultrasonic testing sensors as PULSAR, POLYGON, and PLM belong to the major non-destructive troubleshooting devices. However, the ultrasonic waves of operating frequency attenuate at the depth of $5-10 \mathrm{~cm}$ and fail to penetrate the entire bulk of concrete masonry, making it impossible to consider and evaluate to the full extent the

\footnotetext{
* Corresponding author: Viktor.Shabalin@gmail.com
} 
strength and structural integrity of the reinforced-concrete foundation. From this perspective, it would make sense to use the seismoacoustic approach to survey the entire monolithic concrete stratum. The Far East State Transport University has accumulated a great experience of applying the seismoacoustic sounding technique for monitoring and evaluating the structural integrity of the reinforced-concrete foundation.

\section{The physical fundamentals of the seismoacoustic sounding technique}

The seismoacoustic sounding diagnostic technique is based on the influence of various structural defects on the foundation dynamic characteristics, which are basically resonance frequencies of natural oscillations in the foundation bulk. The resonance frequencies depend on the elastic wave propagation velocity in the foundation, physical dimensions of the engineering structure, and the presence of cavity pockets in concrete masonry. Due to the use of diagnostic techniques based on the Fourier spectrum analysis it is possible to determine the location of abnormal areas in the foundation. According to the theory of compressional-wave propagation, the resonance peak sequence interval is determined by the following formula:

$$
\mathrm{F}(\mathrm{n})=\left(\mathrm{V}_{\mathrm{p}} \times \mathrm{n}\right) / 2 \mathrm{~d},
$$

where $\mathrm{n}=1,2,3 \ldots ; \mathrm{d}$ is the foundation thickness

The resonance peaks beyond this sequence can be attributed to the acoustic reflection response due to irregularities in the foundation bulk. Comparing measured resonance frequencies with rated frequencies, it is possible to determine frequency deviation and identify the location and sizes of cavity pockets in a particular structure.

\section{The target of research and methodology}

The research was targeted at the reinforced-concrete foundation for support № 92 of the power line crossing over the Amur River. The footprint of the foundation is measured $16 \mathrm{~m}$ by $16 \mathrm{~m}$. The rays on Fig. 1 illustrate the acoustic wave propagation in the foundation framework subject to irregularities and cavity pockets. As it is obvious from the schematic view, the wavelength change is reflected on the frequency oscillation spectrum, which is registered by seismic sensors.

Thanks to the in-line seismoacoustic profiling and analysis of the frequency-response characteristics registered by particular sensors, it is possible to identify irregularities, whose elastic properties differ markedly from those of the foundation framework material.

On the basis of the foregoing, the recording system based on the in-line seismoacoustic profiling by means of compression-rarefaction waves of the PH-type has been accepted as the main procedure.

Geophones GX-20DX SUPER, 24-bit analog-digital converter of the sigma-delta modulation system (seismograph station Seismologist 20/24), a hammer fitted with a piezoelectric element, and a set of connecting wire were used by way of digital recordingand-measuring equipment.

Within the scope of research, the inverse goal has to be achieved - to determine and interpret the proportioning of natural vibration frequencies upon specified foundation dimensions and measured velocity of the elastic wave. For the purpose of obtaining the elastic wave velocity in a reinforced-concrete prototype, the surface seismic profiling with a $2-\mathrm{m}$ interval was performed. 


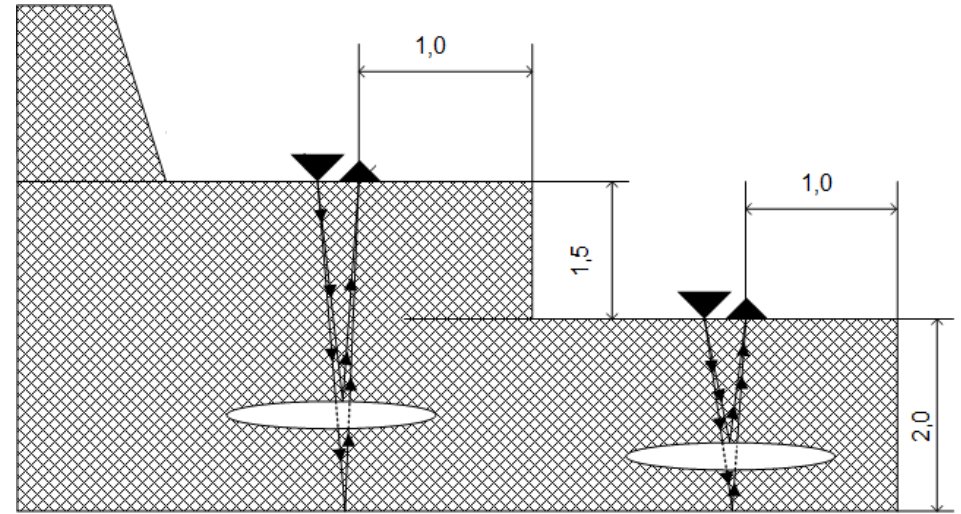

Fig. 1. The pattern of the acoustic wave propagation in the foundation with plane irregularities.

Fig. 2 represents a supervisory recording system for the seismoacoustic sounding of foundation support № 92 for the purpose of obtaining elastic wave velocities in the reinforced-concrete foundation bulk. To guarantee a complete coverage of the prototype structure during field observations, the entire foundation surface was enveloped by a grid, with geophones and vibration points being located at the grid crossing nodes.

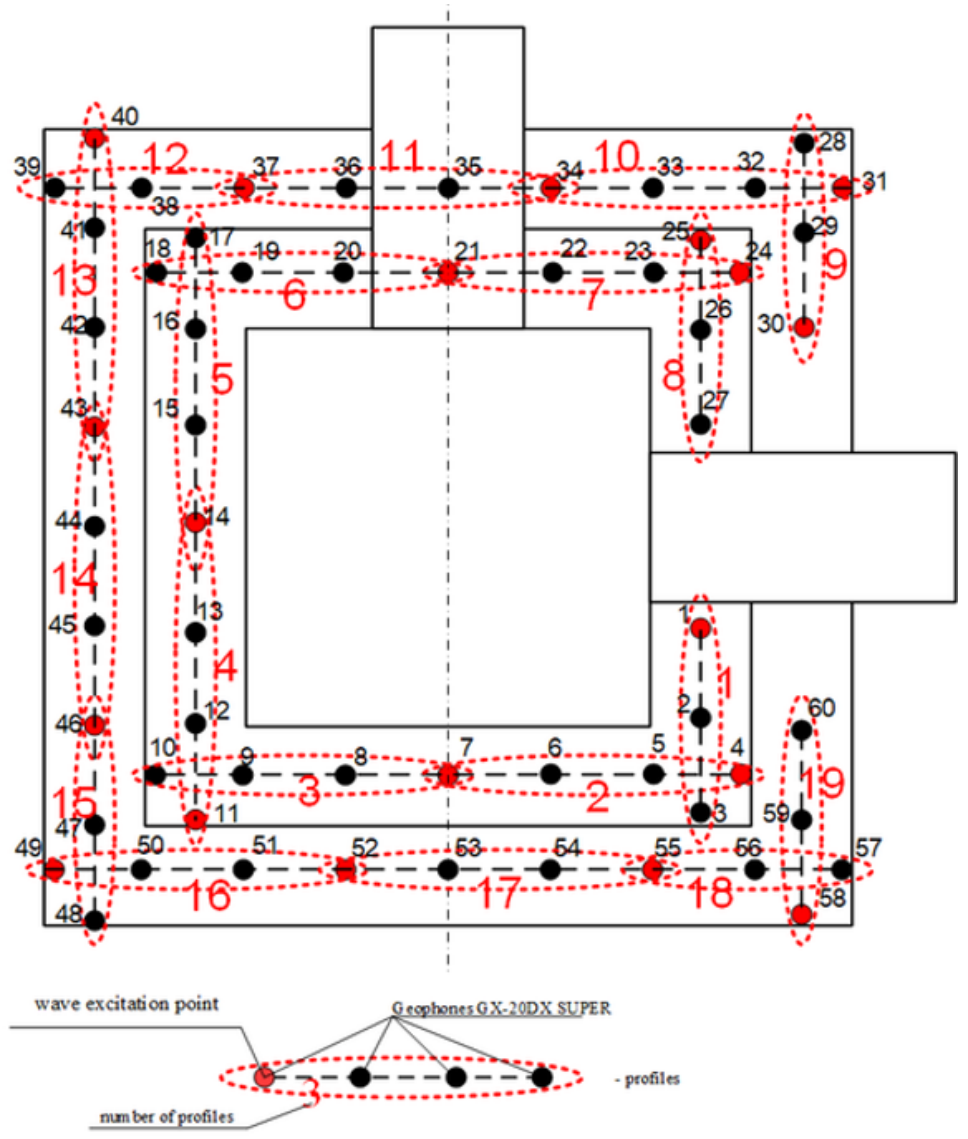

Fig. 2. The location map of profiles and geophones during seismoacoustic sounding.

Fig. 3 represents a seismic data set resulted from the impact effect at point 21 on profile 6 . 


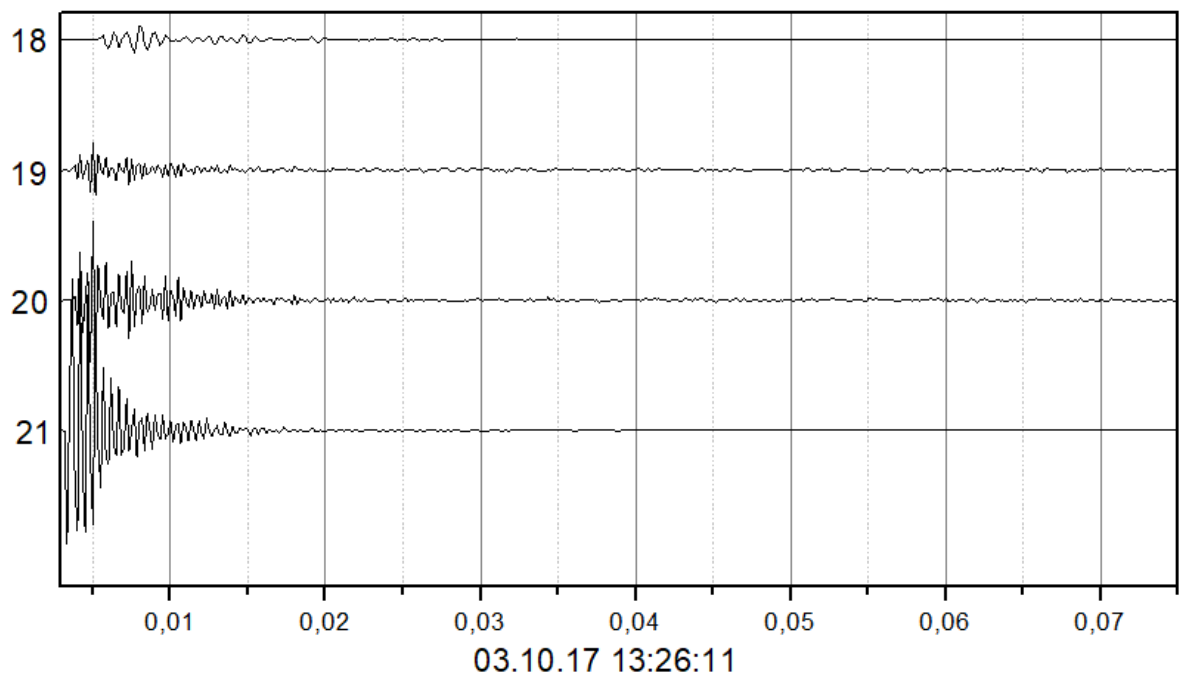

Fig. 3. The seismic data set resulted from the seismoacoustic sounding on profile 6 .

\section{Fundamental results}

The entire research programme encompassed 15 seismoacoustic profiling and 60 seismoacoustic sounding procedures. During the first stage of investigation, the seismoacoustic profiling procedure was applied to analyze the initial arrival of compressional-waves. As a result of seismoacoustic sounding procedure, lateral velocities of 3,850-4,000 meters per second were recorded. After specifying the foundation physical dimensions and lateral velocities at every point, basic amplitude-frequency characteristics were calculated for each foundation bench. The seismic data obtained at every point was subjected to the Fourier transformation (Fig. 4) and the spectrum was designed. The frequency distribution of the compressional-elastic wave in the foundation stratum for the power transmission line support is represented on Fig. 5.

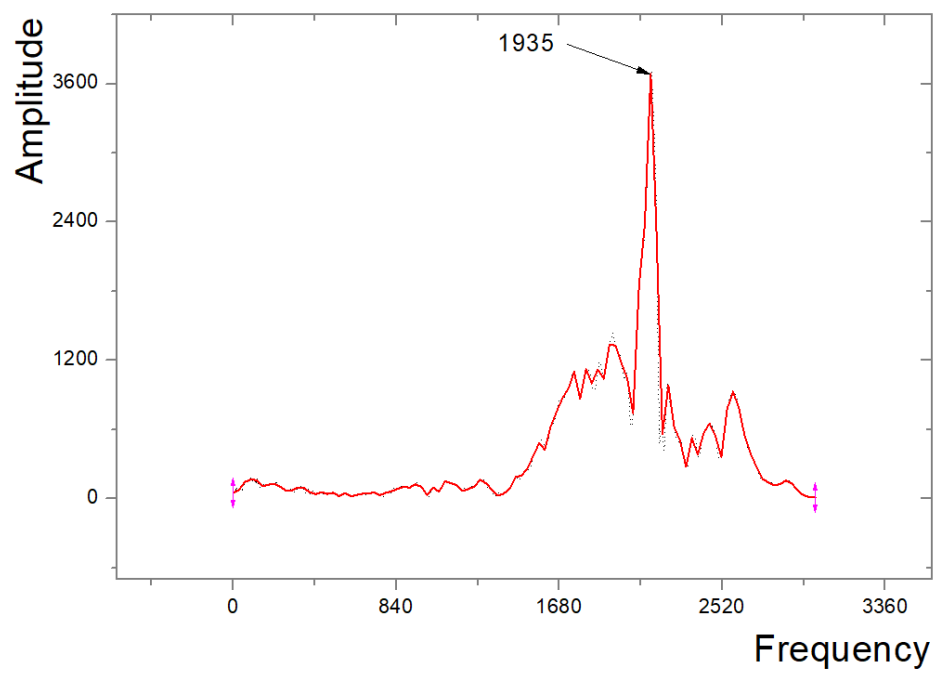

Fig. 4. The Fourier spectrum obtained at seismoacoustic sounding point 59. 


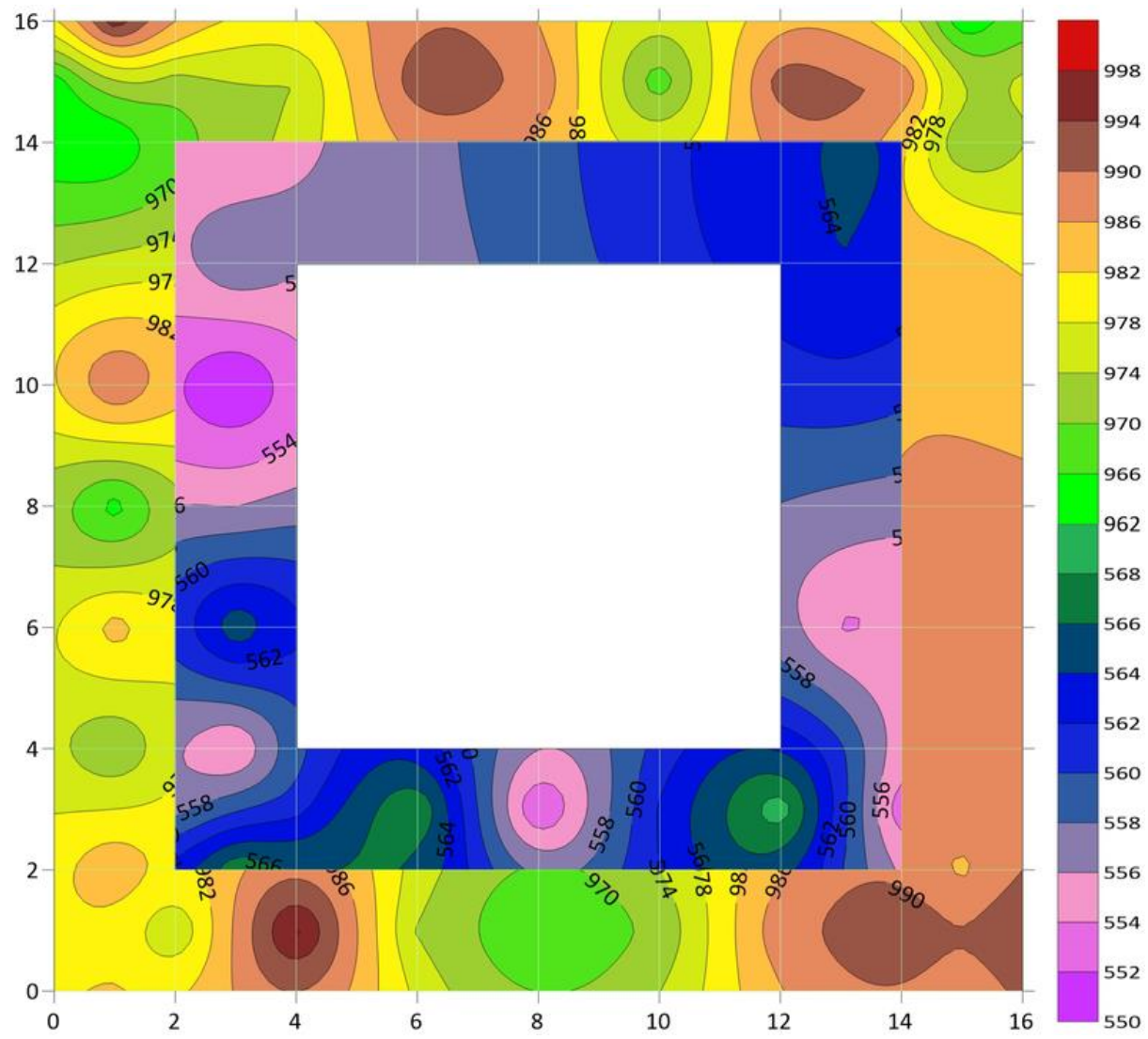

Fig. 5. The proportioning of the main resonance frequency peaks in the foundation bulk of the power transmission line support.

As can be seen from the above, the research on the structural integrity of the reinforcedconcrete foundation for the power transmission line support allows us to arrive at the conclusion that the seismoacoustic sounding technique is the most feasible and appropriate procedure (as compared to similar ultrasonic methods) for the quality evaluation of construction-assembly operations during erection of massive concrete and reinforcedconcrete buildings and related civil engineering structures.

\section{Reference}

1. Russian Standard GOST 17624-87

2. V.V. Kapustin, The Prospecting Seismology Approach 1, 91-99 (2008)

3. B.B. Bromes, Methods of Calculating the Ultimate Bearing Capacity of Piles. Piles a New Force Gauge, and Bearing Capacity Calculations (Stockholm, 1970)

4. Russian Standard SP 13-102-2003

5. Russian Standard GOST R 53778-2010

6. T.H. Hughes, The Finite Element Method. Linear Static and Dynamic Analysis (Prentice Hall Int., 1987)

7. E.A.L. Smith, Journal of the Engineering Mechanics Division, Proceedings of the American Society of Civil Engineers 86-EM4 (1967) 